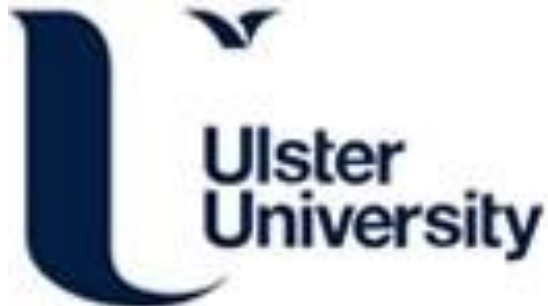

\section{Influence of target surface degradation on the properties of r.f. magnetron-sputtered calcium phosphate coatings}

Boyd, A., Akay, M., \& Meenan, BJ. (2003). Influence of target surface degradation on the properties of r.f. magnetron-sputtered calcium phosphate coatings. Surface and Interface Analysis, 35(2), 188-198. https://doi.org/10.1002/sia.1512

Link to publication record in Ulster University Research Portal

\section{Published in:}

Surface and Interface Analysis

Publication Status:

Published (in print/issue): 01/02/2003

DOI:

10.1002/sia.1512

\section{Document Version}

Publisher's PDF, also known as Version of record

\section{General rights}

Copyright for the publications made accessible via Ulster University's Research Portal is retained by the author(s) and / or other copyright owners and it is a condition of accessing these publications that users recognise and abide by the legal requirements associated with these rights.

\section{Take down policy}

The Research Portal is Ulster University's institutional repository that provides access to Ulster's research outputs. Every effort has been made to ensure that content in the Research Portal does not infringe any person's rights, or applicable UK laws. If you discover content in the Research Portal that you believe breaches copyright or violates any law, please contact pure-support@ulster.ac.uk. 


\title{
Influence of target surface degradation on the properties of r.f. magnetron-sputtered calcium phosphate coatings
}

\author{
A. Boyd, M. Akay and B. J. Meenan*
}

Northern Ireland Bio-Engineering Centre (NIBEC), School of Electrical \& Mechanical Engineering, University of Ulster, Shore Road, Newtownabbey, Co. Antrim BT37 OQB, Northern Ireland, UK

Received 29 July 2002; Revised 27 September 2002; Accepted 27 September 2002

This paper reports a detailed study of how repeated r.f. magnetron sputtering from a hydroxyapatite (HA) powder target affects the nature and reproducibility of a sequential series of thin-film coatings deposited onto Ti6Al4V substrates. An evaluation of the effective lifespan of the HA sputter targets and the reproducibility of the calcium phosphate $(\mathrm{CaP})$ coatings produced from them has been made from Fourier transform infrared spectroscopy, XPS and, as appropriate, atomic force microscopy and SEM/energy dispersive $x$-ray analyses. The annulus region of the target surface, from which sputtering under r.f. magnetron conditions normally occurs, showed severe surface degradation after only one deposition run, as indicated by significant $\mathrm{PO}_{4}{ }^{3-}$ and $\mathrm{OH}^{-}$depletion. This deterioration continued after each subsequent deposition cycle but to a much lesser extent than that observed in the initial sputtering period.

The layers produced from all of the sputter runs contained the expected $\mathrm{Ca}^{2+}$ and $\mathrm{PO}_{4}{ }^{3-}$ species characteristic of a CaP system but were $\mathrm{OH}^{-}$deficient in the as-deposited state. However, the chemical and morphological properties of the coatings did not change significantly until after the third consecutive sputter cycle. Hence, these data indicate that, even though a significant level of degradation of the HA target occurs at the outset of the sputtering procedure, the general plasma conditions employed here have a dominant influence on the coating properties until a critical degradation condition is met. As such, the compacted HA powder targets of interest can have a life-cycle greater than single usage without detriment to the chemistry and morphology of the coatings produced from them. Copyright $(2) 2003$ John Wiley \& Sons, Ltd.

KEYWORDS: Calcium phosphate thin films; r.f. magnetron sputtering; sputter target lifespan; surface analysis

\section{INTRODUCTION}

Owing to their excellent inherent bioactivity, many calcium phosphate $(\mathrm{CaP})$ bioceramics, particularly hydroxyapatite $\left(\mathrm{HA}, \mathrm{Ca}_{10}\left(\mathrm{PO}_{4}\right)_{6}(\mathrm{OH})_{2}\right)$, have received considerable attention for clinical applications involving hard-tissue implant devices. ${ }^{1,2}$ Limitation to their use is generally due to the poor mechanical properties they exhibit in bulk form. Coatings of HA and other CaP materials on mechanically superior materials, such as metals and metal alloys, can be used to overcome some of these problems and provide direct bone apposition in a medical implant context, thereby improving the potential for early fixation of several types of orthopaedic device. ${ }^{3}$ Such coatings may be applied to the implant surfaces by a variety of methods, including plasma spraying, ${ }^{4}$ radiofrequency (r.f.) magnetron sputtering, ${ }^{5}$ electrophoretic deposition, ${ }^{6}$ dip coating ${ }^{7}$ and pulsed laser deposition (PLD). ${ }^{8}$

*Correspondence to: B. J. Meenan, Northern Ireland Bio-Engineering Centre (NIBEC), School of Electrical \& Mechanical Engineering, University of Ulster, Shore Road, Newtownabbey, Co. Antrim BT37 OQB, Northern Ireland, UK.

E-mail: bj.meenan@ulster.ac.uk
Plasma spraying is the most commonly employed commercial method for applying HA coatings. ${ }^{4,9}$ However, there are several areas of concern regarding the performance of these coatings in vivo. ${ }^{10}$ Although r.f. magnetron sputtering, which is used extensively in the electronics industry, has been utilized previously for the deposition of bioceramic layers, the technique has yet to find a major clinical application. Notwithstanding this lack of commercial medical application, it is clear that sputtering can offer significant advantages over plasma spraying and several other coating methodologies. The influence of key deposition parameters, such as discharge power level, ${ }^{11}$ process chamber pressure and gas composition, ${ }^{12,13}$ on the properties of CaP coatings have been reported previously. These studies clearly indicate that the chemical and structural features of sputtered layers can be manipulated to enhance and control their biofunctionality. In addition, the technique has the ability to coat substrates with non-planar geometry. ${ }^{5}$

Given this flexibility, coatings with specific predetermined properties can be created to add significant value to surface conditions where the manipulation of biological species is important. It is likely, then, that these advantages 
will find expression in delivering the conditions required for influencing cell-surface interactions, such as those required in the rapidly emerging field of tissue engineering. However, the effective utilization of the sputtering process is critically dependent on the ability to control those parameters that provide reproducible coatings with the required predetermined properties. In this context, the longevity of the bioceramic sputter targets is an obvious consideration for providing a stable and cost-effective sputtering process. The nature of the target material and the processing conditions that it is exposed to during deposition can have a major influence on the properties of the thin-film coatings produced, particularly if it is used in a repetitive manner.

Most of the work published to date on r.f. magnetron sputter deposition of $\mathrm{CaP}$ coatings relates to single-use sputter targets, which are normally plasma sprayed onto conductive backing plates. ${ }^{14-17}$ However, such targets are less than ideal because the spraying process used for their manufacture may result in the formation of amorphous $\mathrm{HA}$ and/or other non-bioactive CaP phases. ${ }^{4}$ It has been suggested previously ${ }^{18,19}$ that target material stoichiometry can have a significant influence on the characteristics of sputter deposited coatings. Hence, the use of compacted HA powder targets is desirable due to the attendant ability to change readily the stoichiometry and phase of the precursor powder in order to reflect these properties in the subsequent $\mathrm{CaP}$ coatings. In this regard, the effective lifespan of HA powder targets and the effects of their multi-cycle usage on the composition and structure of the resultant coatings are of considerable importance.

Accordingly, this paper reports a study of the effects of repeated usage of HA targets comprised of compacted powder on the structural and compositional properties of a series of thin-film CaP coatings deposited onto Ti6Al4V substrates by r.f. magnetron sputtering. A sequence of four individual sputter deposition runs has been carried out on each of the targets and their effective lifespan assessed in terms of the surface properties of the resulting annular sputter zone. Changes in the corresponding coating characteristics have been determined and related to the target surface condition from which they originate. Chemical and morphological properties of both the HA targets and the $\mathrm{CaP}$ coatings have been determined by Fourier transform infrared spectroscopy (FTIR), x-ray photoelectron spectroscopy (XPS), atomic force microscopy (AFM) and scanning electron microscopy (SEM) in conjunction with associated energy-dispersive $\mathrm{x}$-ray (EDX) analysis.

\section{MATERIALS AND METHODS}

\section{Materials}

Hydroxyapatite powder (Merck KGaA, Germany) was pressed at $40 \mathrm{kN}$ for $2 \mathrm{~h}$ using a pressure filtration die assembly to produce $76 \mathrm{~mm}$ diameter discs that are $5 \mathrm{~mm}$ thick. These HA targets were bonded to a $1 \mathrm{~mm}$ thick lowoxygen copper backing plate using a silver-loaded epoxy resin (Acheson Electrodag 5915) and cured at $120^{\circ} \mathrm{C}$ for $1 \mathrm{~h}$. The thermal conductivity of the copper helps to dissipate the heat generated in the target during operation of the sputter source, thereby enhancing its mechanical integrity in situ.
Coatings were sputter deposited from the compacted HA targets onto medical-grade Ti6Al4V (Titanium International Ltd., UK) substrates $(20 \mathrm{~mm} \times 20 \mathrm{~mm} \times 0.5 \mathrm{~mm})$. The substrates used had been abraded with silicon carbide paper (1200 grade) and sonicated in acetone for $30 \mathrm{~min}$ and then deionized water for $15 \mathrm{~min}$ before being dried for $12 \mathrm{~h}$ at $110^{\circ} \mathrm{C}$. This provides a slightly roughened and more uniform surface onto which the CaP sputtered layer can better adhere.

\section{Sputtering procedure}

Radio frequency magnetron sputtering was performed using a high-vacuum (base pressure $5 \times 10^{-6} \mathrm{mbar}$ ) Torus $3 \mathrm{M}$ sputtering source (Kurt J. Lesker Ltd, USA) operating at 13.56 MHz. An impedance matching network (Advanced Energy, UK) was used to minimize the reflected power. Prior to the first deposition run, a power ramp-up phase was conducted as follows: $20 \mathrm{~W}$ for $10 \mathrm{~h}, 50 \mathrm{~W}$ for $2 \mathrm{~h}$ and $100 \mathrm{~W}$ for $2 \mathrm{~h}$. This thermally conditions the compacted HA powder targets prior to deposition.

A series of four sequential r.f. magnetron sputter deposition runs was performed, with each target employing the conditions given in Table 1 . Before runs 2, 3 and 4, a power ramp of $30 \mathrm{~min}$ at 20,50 and $100 \mathrm{~W}$ was used to stabilize thermally the compacted discs. Extensive experience of using this type of powder target indicates that they exhibit significant cracking after four sequential deposition runs under the experimental conditions employed here. This type of damage may result in co-sputtering of the bonding agent and/or copper backing plate, therefore this study was limited to the use of four deposition cycles from an individual target.

\section{Characterization of sputtered coatings and residual target surfaces}

Coatings from each of the four sequential deposition runs were analysed by FTIR, XPS and AFM. The sputtered annular 'racetrack' region on the HA targets that had undergone one, two, three and four deposition cycles were examined similarly. In addition, SEM/EDX was carried out on the residual powder target surfaces.

The FTIR spectra for scrapings taken from target surfaces after each of the deposition periods of interest were recorded on a Biorad FTS 3000MX instrument equipped with a Pike Easidiff diffuse reflectance accessory. Samples were analysed

Table 1. Operational parameters employed during r.f. magnetron sputter deposition of $\mathrm{CaP}$ coatings

\begin{tabular}{lc}
\hline Coating parameters & Conditions employed \\
\hline Base pressure & $5 \times 10^{-6} \mathrm{mbar}$ \\
Working gas & Argon \\
Power (r.f.) & $150 \mathrm{~W}$ \\
Chamber pressure & $1 \times 10^{-2} \mathrm{mbar}$ \\
Gas flow rate & $5 \mathrm{Sccm}$ \\
Throw distance & $100 \mathrm{~mm}$ \\
Substrate temperature & $60 \pm 8^{\circ} \mathrm{C}$ \\
Sputtering time & $3 \mathrm{~h}$ \\
Coating thickness & $158 \pm 6 \mathrm{~nm}$ \\
\hline
\end{tabular}


at $4000-400 \mathrm{~cm}^{-1}$ in absorbance mode at a resolution of $4 \mathrm{~cm}^{-1}$, with 64 scans recorded per sample.

XPS analysis of coatings and residual target surfaces was carried out in a Scienta ESCA 300 XPS system using $\mathrm{Al} \mathrm{K} \alpha$ x-rays $(h v=1486.6 \mathrm{eV})$ operating at a pass energy of $150 \mathrm{eV}$. In situ, charge compensation control was achieved by setting the instrument's low-energy electron flood gun to $2.0 \mathrm{eV}$. As required, the measured binding energy (BE) positions were corrected further for shifts due to sample charging by setting the lowest $\mathrm{BE}$ component of the $\mathrm{C} 1 \mathrm{~s}$ spectral envelope to $285.0 \mathrm{eV}$, which is the value generally accepted for adventitious carbon contamination. Deconvolution of the C 1s (275-300 eV), O 1s (525-545), Ca $2 p(340-360)$ and P $2 p(125-150)$ regions was undertaken by subtraction of a linear background and application of a mixed Gaussian-Lorentzian synthetic peak. Full width at half-maximum (FWHM) values for each component were in the range 1.6-1.8 eV and other parameters were applied as part of the instrument-specific curve-fitting routine.

The AFM studies of the surface topography of the CaP coatings on Ti6Al4V were carried out using a Digital Instruments Dimension 3000 scanning probe microscope. The instrument was operated in tapping mode $(75 \mathrm{kHz})$ over a $2 \mu \mathrm{m} \times 2 \mu \mathrm{m}$ area using a force-modulated etched silicon probe (FESP) with a nominal force constant of $0.28 \mathrm{~N} \mathrm{~m}^{-1}$. The images collected were subjected to minimal computational manipulation, with only tilt removal applied here.

The SEM images of the target surfaces and associated EDX measurements were performed on a Hitachi S-3200N variable-pressure instrument equipped with a Link ISIS $x$ ray microanalysis system (Oxford Instruments). Images were obtained in backscatter electron mode using an acceleration voltage of $30 \mathrm{keV}$ at a working distance of $15-20 \mathrm{~mm}$ at focus. An argon pressure of $\sim 22.5$ mTorr was required to eliminate charge distortion. The EDX analysis was carried out under these general operating conditions at $\times 400$ magnification and for an analysis time of $60 \mathrm{~s}$ per sample. Quantitative data were obtained by comparing the peak intensities for the elements detected in the samples with those from a cobalt standard. The actual compositional values for each of the elements were obtained by using the relevant standardized ZAF correction factors.

\section{RESULTS AND DISCUSSION}

\section{Characterization of the HA powder and sputter target surfaces}

Figure 1 shows optical and SEM images of the surface region of a compacted HA powder target prior to sputter deposition and after it has undergone four sequential deposition cycles at $150 \mathrm{~W}$. This implies a total of $12 \mathrm{~h}$ of sputtering time at this power plus the corresponding target break-in time. The later image [Fig. 1(b,i)] clearly shows a concentric ring or 'annular racetrack' (A), the presence of which is due to the use of a magnetron sputter source. This obvious region of surface damage was easily recognizable for all the depositions carried out on these compacted powder targets. Subsequent SEM, FTIR and XPS analyses were carried on region $A$ and on the edge $(E)$ and the middle $(\mathrm{M})$ of the target. The hairline cracking observed on the target surface is associated with residual thermal mismatch between the target and the copper backing plate, and occurs after the first sputter run. This effect occurred across the uppermost region of the target surface only and was monitored closely after each deposition cycle to ensure that the copper backing plate was not exposed, because this might lead to the incorporation of copper or silver from the bonding epoxy into the CaP films.

The SEM image of the target surface region prior to any sputtering [Fig. 1(a,ii)] shows small compacted grains of HA that are visible over the entire disc surface. The associated EDX analysis data are reported in Table 2. The pristine target gave a $\mathrm{Ca} / \mathrm{P}$ ratio of $1.74 \pm 0.04$, which is slightly higher than the value expected for stoichiometric HA at 1.67 but is consistent with previous analysis of this source material. ${ }^{20,21}$ The SEM image of the sputtered target annulus region (A) after four deposition cycles [Fig. 1(b,ii)] exhibits irregular columns running parallel to the surface normal and what appear to be loose needle-like crystals perpendicular to the normal. This would suggest that significant degradation of the target material has occurred in this region, where the sputtering process is most intense. This pronounced change in the surface morphology with sputtering also may indicate a phase change in the HA material. The EDX analysis of the sputtered annulus region (A) of the target surface after each of the four sequential depositions (Table 2) shows $\mathrm{Ca} / \mathrm{P}$ ratios with a maximum value of 2.31 after run 4 . This behaviour is indicative of phosphorus depletion in this region.

Figure 2 illustrates a typical FTIR spectrum for the asreceived HA precursor powder in the range $4000-400 \mathrm{~cm}^{-1}$. Absorption bands characteristic of $\mathrm{P}-\mathrm{O}$ stretching vibrations can be observed at 1097, 1036 and $963 \mathrm{~cm}^{-1}$, whereas $\mathrm{O}-\mathrm{P}-\mathrm{O}$ bending vibrations can be seen at 603 and $566 \mathrm{~cm}^{-1} .^{22-24}$ The bands at 3571 and $630 \mathrm{~cm}^{-1}$ are indicative of $\mathrm{O}-\mathrm{H}$ stretching and $\mathrm{O}-\mathrm{H}$ librational bands, respectively. ${ }^{25,26}$ The broad band in the range $3700-3000 \mathrm{~cm}^{-1}$ can be attributed to traces of water, ${ }^{22,27}$ with the band at $\sim 1640 \mathrm{~cm}^{-1}$ being indicative of the bending mode of $\mathrm{H}-\mathrm{O}-\mathrm{H}$ groups from the surface-bound water molecules. ${ }^{26,28}$ Carbonate $\left(\mathrm{CO}_{3}{ }^{2-}\right)$ was also detected as weak bands occurring at 1415, 1458 and $1543 \mathrm{~cm}^{-1}$ and an asymmetrical envelope centred at $879 \mathrm{~cm}^{-1} \cdot 23,24,29-31$ These results indicate that this $\mathrm{HA}$ material has $\mathrm{CO}_{3}{ }^{2-}$ substituted at both the $\mathrm{OH}^{-}$and $\mathrm{PO}_{4}{ }^{3-}$ positions in the hexagonal lattice. $^{30,31}$ The weak bands in the range $2200-2000 \mathrm{~cm}^{-1}$ are associated with vibrational overtones and combination bands of the various spectral components. ${ }^{32}$ Identical FTIR spectra were obtained for scrapings that were taken from the surface and subsurface of the HA target prior to sputter deposition.

An FTIR spectrum for scrapings taken from the uppermost surface of the sputtered annular 'racetrack' region (A) after the first of the four sequential depositions is shown in Fig. 3(a). Compared with the scan for the HA powder, there is an increase in the number of shoulders observed in the $\mathrm{P}-\mathrm{O}$ stretching region between 1200 and $900 \mathrm{~cm}^{-1}$. In addition, the $\mathrm{O}-\mathrm{H}$ vibrational modes at 3570 and $630 \mathrm{~cm}^{-1}$ are less intense. Such features can be attributed to the presence of a dehydroxylated HA phase, which is most likely to be 


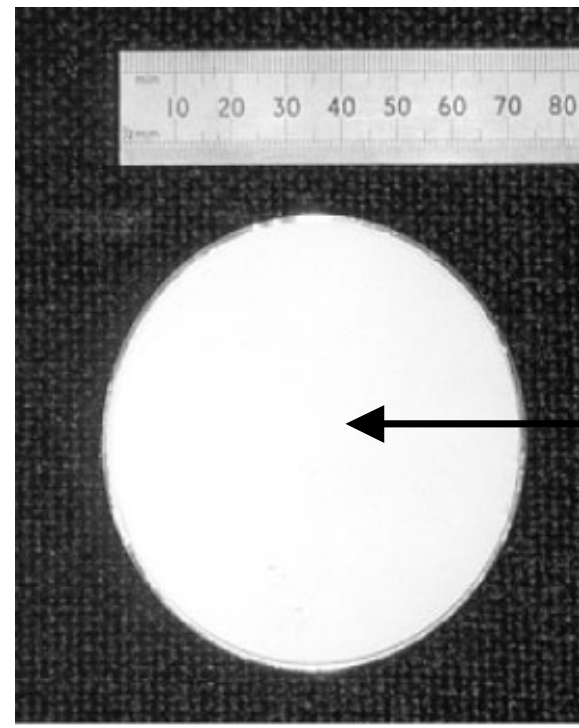

(i)

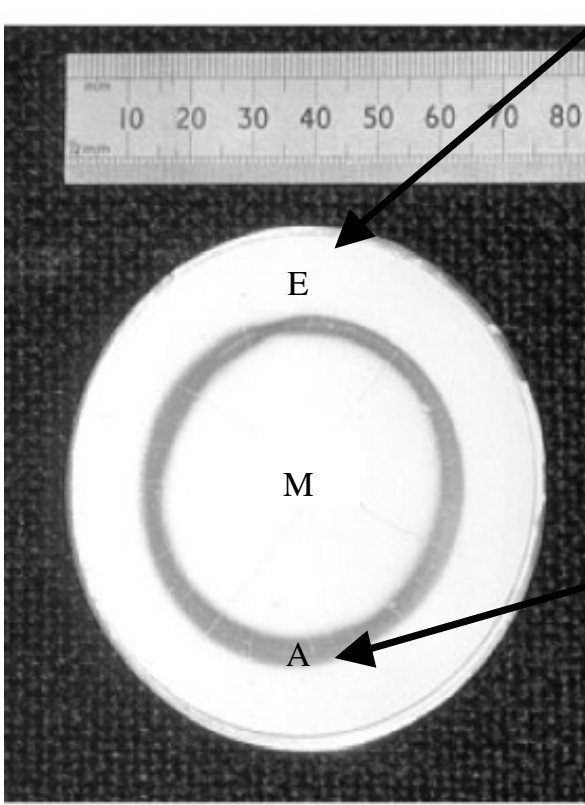

(a)

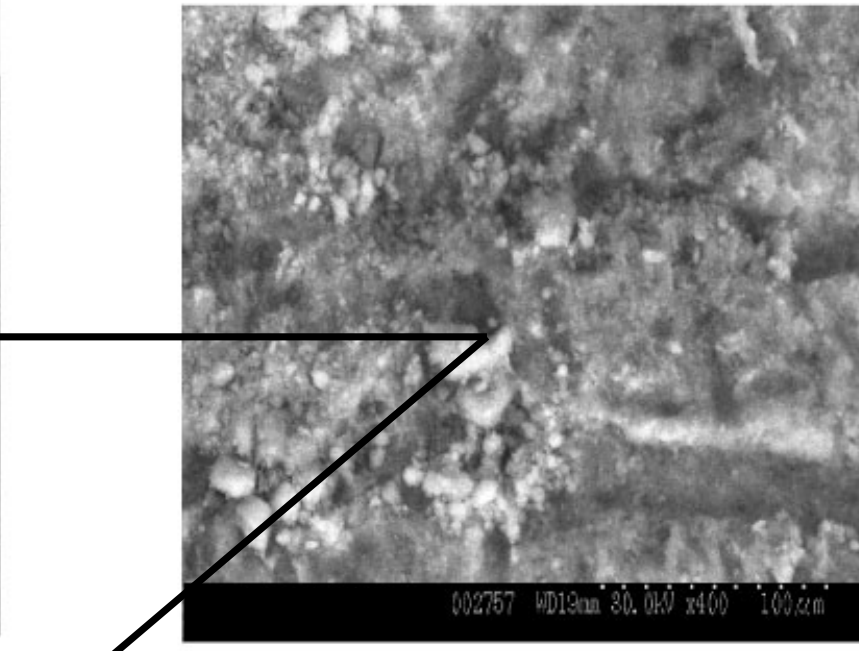

(ii)

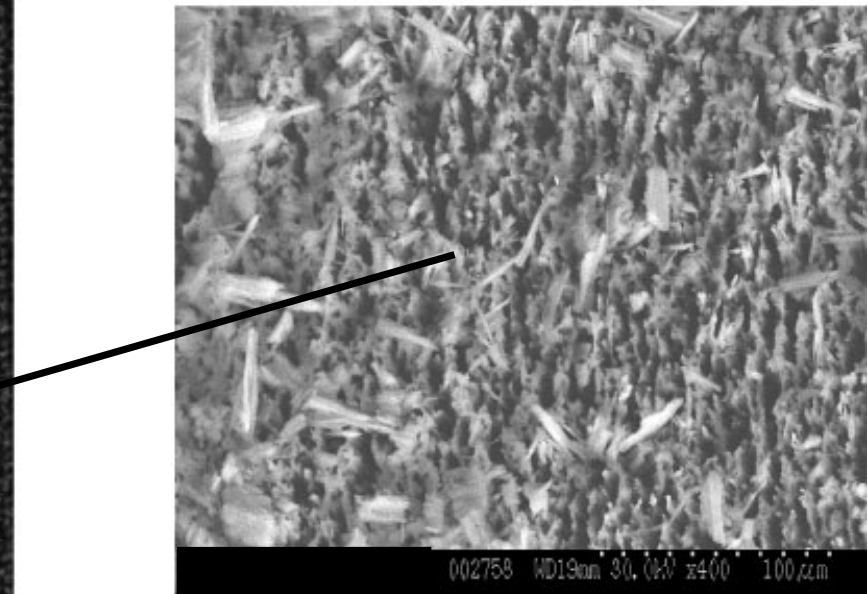

(b)

Figure 1. Optical (i) and SEM (ii) images of HA powder target (a) prior to deposition and (b) after the four sequential r.f. magnetron sputter deposition cycles. Region $\mathrm{A}$ is the sputtered annular racetrack, region $\mathrm{E}$ is the edge of the target and region $\mathrm{M}$ is the middle of the target.

Table 2. The EDX data for the HA target annulus region (A) before and after sputter runs $1-4$

\begin{tabular}{lcccc}
\hline & \multicolumn{4}{c}{$\%$ Atomic concentration } \\
\cline { 2 - 5 } Sample & $\mathrm{Ca}$ & $\mathrm{P}$ & $\mathrm{O}$ & $\mathrm{Ca} / \mathrm{P}$ \\
\hline HA (Merck) powder & $17.70 \pm 1.03$ & $10.62 \pm 0.65$ & $71.68 \pm 1.68$ & $1.67 \pm 0.02$ \\
Target (as received) & $19.91 \pm 0.51$ & $11.47 \pm 0.17$ & $68.62 \pm 0.64$ & $1.74 \pm 0.04$ \\
Target (A), run 1 & $27.56 \pm 1.92$ & $14.03 \pm 0.70$ & $58.43 \pm 1.68$ & $1.97 \pm 0.19$ \\
Target (A), run 2 & $36.60 \pm 1.14$ & $16.90 \pm 0.90$ & $46.53 \pm 1.15$ & $2.17 \pm 0.14$ \\
Target (A), run 3 & $34.67 \pm 0.14$ & $17.80 \pm 0.85$ & $47.37 \pm 1.52$ & $1.94 \pm 0.06$ \\
Target (A), run 4 & $37.20 \pm 1.80$ & $16.07 \pm 1.29$ & $46.73 \pm 1.28$ & $2.31 \pm 0.27$ \\
\hline
\end{tabular}




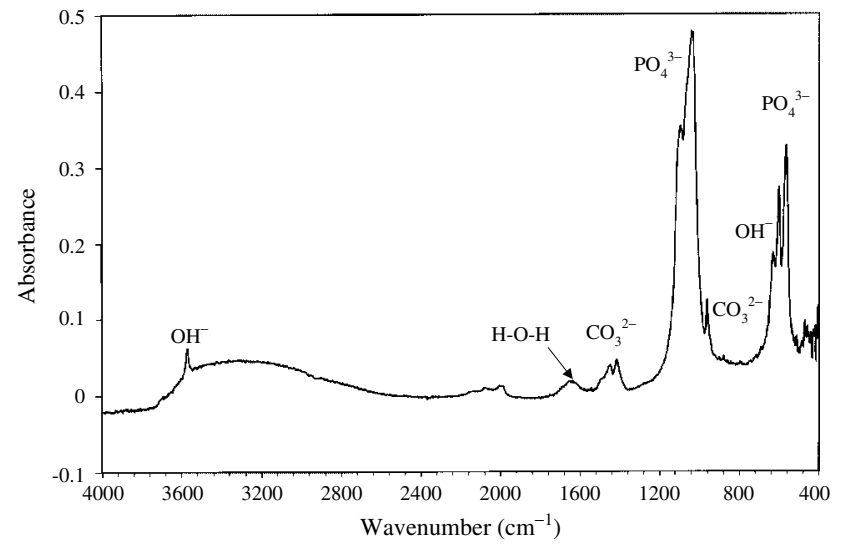

Figure 2. Typical FTIR spectrum $\left(4000-400 \mathrm{~cm}^{-1}\right)$ for $\mathrm{HA}$ target material.

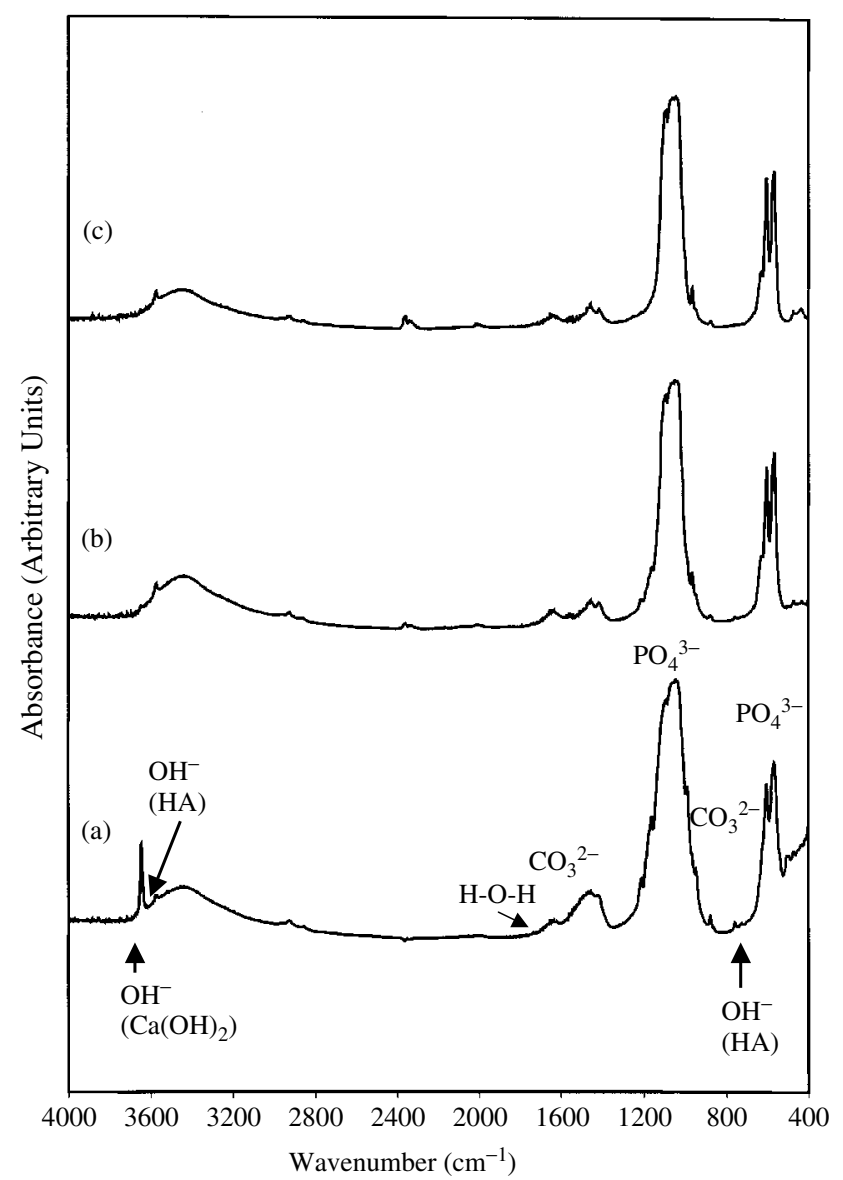

Figure 3. The FTIR spectra $\left(4000-400 \mathrm{~cm}^{-1}\right)$ for scrapings taken from the annulus region (A) of HA target after four sequential sputter runs: (a) the uppermost surface; (b) the sub surface; (c) beneath the sub surface.

oxyhydroxyapatite $\left(\mathrm{OHA}, \mathrm{Ca}_{10}\left(\mathrm{PO}_{4}\right)_{6}(\mathrm{OH})_{2} \cdot 2_{x} \mathrm{O}_{x}\right)$, where $x$ implies a lattice vacancy. These results suggest the presence of OHA rather than tricalcium phosphate (TCP, $\left.\mathrm{Ca}_{3}\left(\mathrm{PO}_{4}\right)_{2}\right)$ because a weak $\mathrm{O}-\mathrm{H}$ stretching mode at $3570 \mathrm{~cm}^{-1}$ is still observed here. This band is more closely associated with a partially hydroxylated HA system rather than TCP. ${ }^{33}$ In addition, $\mathrm{P}-\mathrm{O}$ stretching vibrations, attributable to octacalcium phosphate $\left(\mathrm{OCP}, \mathrm{Ca}_{8} \mathrm{H}_{2}\left(\mathrm{PO}_{4}\right)_{6}\right)$, are clearly present. ${ }^{34,35}$
Significant carbonate bands were observed between $1500-1400 \mathrm{~cm}^{-1}$ and $900-850 \mathrm{~cm}^{-1} \cdot 30,31$ A strong O-H stretching mode, not associated with $\mathrm{HA}$, occurs at $3640 \mathrm{~cm}^{-1}$ and is assigned to $\mathrm{Ca}(\mathrm{OH})_{2} \cdot{ }^{36}$ These data indicate that the HA material has undergone obvious degradation during sputtering, thereby producing other $\mathrm{CaP}$ phases and $\mathrm{Ca}(\mathrm{OH})_{2}$. A further two scrapings were taken from this region of the target and analysed by FTIR, as shown in Figs 3(b) and 3(c). These spectra are consistent with those observed for the pristine HA powder and therefore confirm that the degradation of HA in the sputtered annulus region (A) is a surface phenomenon not related to the target bulk. The FTIR spectra taken from areas towards the middle (M) and edge (E) of the targets also indicate the presence of pristine HA, with no evidence of any degradation species. Similar FTIR spectra are observed for scrapings taken from target surfaces after the second, third and fourth sputter deposition cycles.

An XPS survey scan (not shown here) for the asreceived HA precursor powder prior to target formation confirmed that the uppermost surface layer of this material contains only calcium, phosphorus, oxygen and carbon, i.e. C 1s $(285.0 \mathrm{eV}), \mathrm{O} 1 \mathrm{~s}(531.1 \mathrm{eV}), \mathrm{Ca} 2 \mathrm{p}_{3 / 2}(347.3 \mathrm{eV}), \mathrm{P} 2 \mathrm{p}$ (133.4 eV), Ca 3s (44.2 eV), Ca 3p $p_{1 / 2}(25.3 \mathrm{eV}), \mathrm{P} 2 \mathrm{~s}(191.2 \mathrm{eV})$, Ca 2s (439.0 eV), O KLL (764 eV) and Ca LMM (964 eV) peaks were observed. These values correspond closely to those reported in the literature for HA.${ }^{37}$ No other elemental species were observed at the limit of detection for the instrument used ( $\sim 0.1 \%$ atomic concentration).

Expanded XPS scans for the C 1s, O 1s, Ca $2 p$ and P $2 p$ regions of the HA material are shown in Fig. 4. These plots were used to determine the various quantitative data given in Table 3. The C 1s region [Fig. 4(a)], has been curve fitted with three different components. The dominant peak $(285.0 \mathrm{eV})$ is attributed to hydrocarbon species, i.e. C-C and/or $\mathrm{C}-\mathrm{H}$, present as a result of adventitious carbon contamination. $^{38,39,41}$. The other peaks at 286.6 and $289.0 \mathrm{eV}$ are indicative of oxygen-bonded carbon ${ }^{38-40}$ and a carbonate $\left(\mathrm{CO}_{3}{ }^{2-}\right)$ species, ${ }^{41,42}$ respectively. The corresponding $\mathrm{O} 1 \mathrm{~s}$ peak [Fig. 4(b)] can be deconvoluted into two separate peaks. The most intense component at $531.1 \mathrm{eV}$ corresponds to an O-P-bonded species ${ }^{38,43}$ and the second peak at $532.5 \mathrm{eV}$ can be attributed to oxygen bonded to carbon and/or an $\mathrm{OH}^{-}$ species. The Ca 2 p region for this material [Fig. 4(c)] exhibits a well-resolved doublet with a Ca $2 \mathrm{p}_{3 / 2}$ component at $347.3 \mathrm{eV}$ and a Ca $2 \mathrm{p}_{1 / 2}$ component at $350.9 \mathrm{eV} .^{38}$ The Ca $2 \mathrm{p}_{1 / 2}$ and $\mathrm{Ca} 2 \mathrm{p}_{3 / 2}$ bands are separated by $\sim 3.6 \mathrm{eV}$ and have the correct relative intensity ratio of $3: 1$. The corresponding $\mathrm{P} 2 \mathrm{p}$ band is shown in Fig. 4(d) as an unresolved doublet with an average $\mathrm{BE}$ position of $133.4 \mathrm{eV}$. The $\mathrm{Ca} / \mathrm{P}$ ratio for this material, calculated from these XPS data, is $1.76 \pm 0.17$ (Table 3), which is slightly higher than the expected theoretical value of 1.67 for stoichiometric $\mathrm{HA}^{3}$ but is almost identical to the value obtained from EDX analysis.

The XPS analysis of the target surface prior to deposition illustrates spectral features matching those of the HA precursor powder described above, indicating again the presence of calcium, phosphorus, oxygen and carbon peaks. Deconvolution of the $\mathrm{C} 1 \mathrm{~s}, \mathrm{O} 1 \mathrm{~s}, \mathrm{Ca} 2 \mathrm{p}$ and $\mathrm{P} 2 \mathrm{p}$ bands showed similar spectral fits to those observed for the HA 

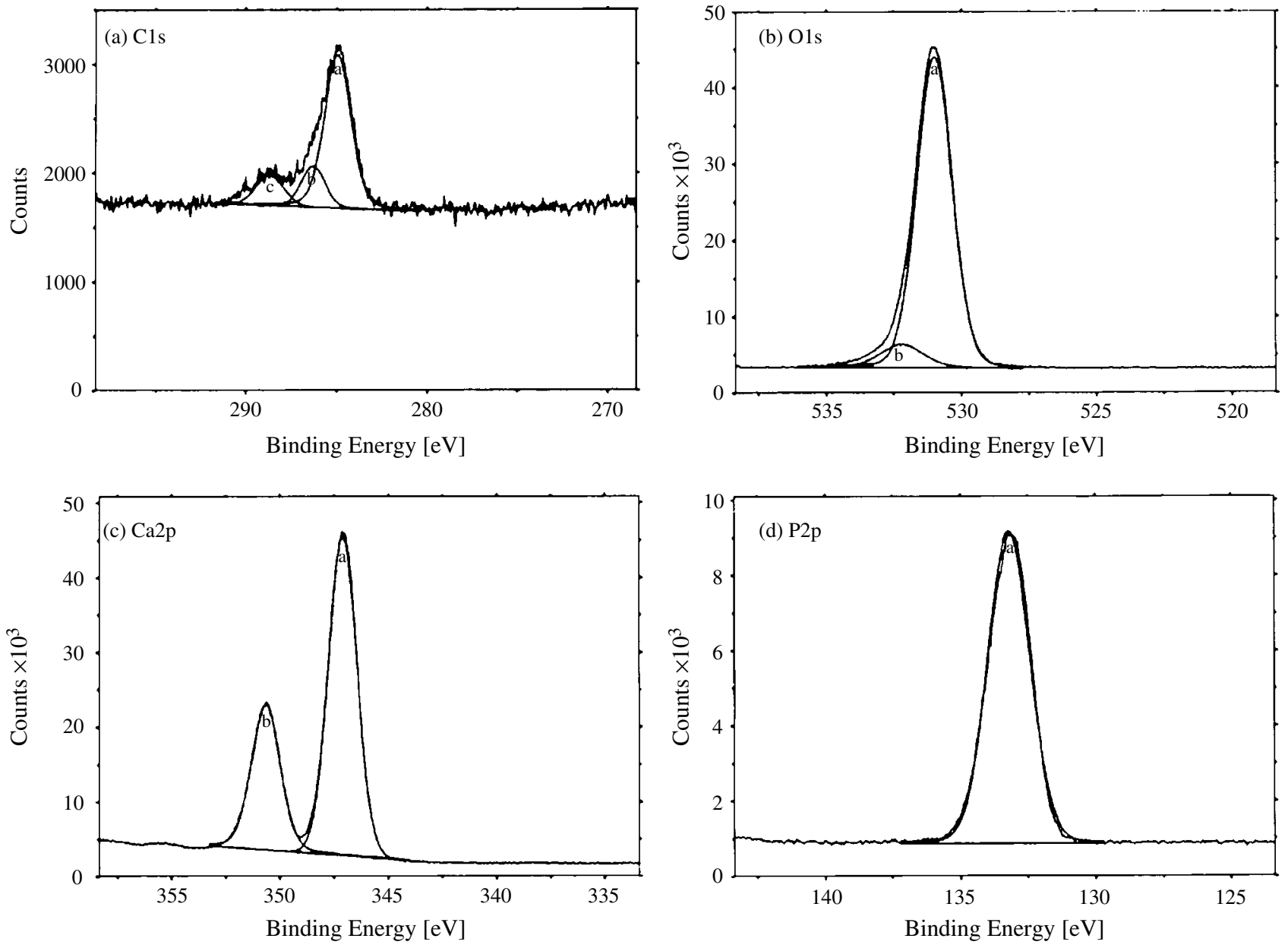

Figure 4. Deconvoluted XPS spectra for (a) C 1s (269-301 eV), (b) O 1s (519-537 eV), (c) Ca 2p (344-357 eV) and (d) P 2p (124-144 eV) regions of HA powder target.

Table 3. The XPS data for the HA target before and after sputter runs 1-4

\begin{tabular}{|c|c|c|c|c|c|c|c|c|c|}
\hline \multirow[b]{2}{*}{ Sample } & \multicolumn{4}{|c|}{$\mathrm{BE}(\mathrm{eV})^{\mathrm{a}}$} & \multicolumn{4}{|c|}{$\%$ Atomic concentration } & \multirow[b]{2}{*}{$\mathrm{Ca} / \mathrm{P}$} \\
\hline & C 1s & $\mathrm{O} 1 \mathrm{~s}$ & $\mathrm{Ca} 2 \mathrm{p}_{3 / 2}$ & P $2 p$ & $\mathrm{C} 1 \mathrm{~s}$ & $\mathrm{O} 1 \mathrm{~s}$ & Ca $2 p$ & $P 2 p$ & \\
\hline Target (as received) & 285.0 & 531.0 & 347.1 & 133.2 & 4.6 & 60.4 & 22.7 & 12.3 & 1.84 \\
\hline Target (A), run 1 & 285.0 & 531.3 & 347.0 & 133.1 & 15.8 & 60.1 & 21.1 & 3.1 & 7.80 \\
\hline Target (A), run 2 & 285.0 & 531.5 & 347.2 & 133.0 & 12.4 & 63.4 & 20.9 & 3.3 & 6.45 \\
\hline Target $(\mathrm{A})$, run 3 & 285.0 & 531.3 & 347.1 & 133.2 & 14.0 & 61.2 & 21.2 & 3.5 & 6.13 \\
\hline Target (A), run 4 & 285.0 & 531.5 & 347.3 & 133.1 & 12.7 & 61.6 & 21.1 & 4.6 & 5.05 \\
\hline Target $(\mathrm{M})$, run 4 & 285.0 & 531.5 & 347.4 & 133.2 & 19.9 & 57.4 & 14.8 & 7.9 & 1.87 \\
\hline Target $(\mathrm{E})$, run 4 & 285.0 & 531.0 & 347.3 & 132.7 & 20.1 & 54.6 & 16.7 & 8.6 & 1.84 \\
\hline
\end{tabular}

${ }^{a}$ Most intense photoelectron line for each element detected.

powder. The relevant quantitative data are reported in Table 3. The $\mathrm{Ca} / \mathrm{P}$ ratio for the uppermost surface of the target, as determined using XPS, was 1.84 . This value is higher than that measured for this HA material in its pristine powder form and may reflect surface segregation of calcium to the uppermost surface, which occurs from mechanical loading during target formation.

By comparison, deconvolution of the $\mathrm{C} 1 \mathrm{~s}, \mathrm{O} 1 \mathrm{~s}, \mathrm{Ca} 2 \mathrm{p}$ and P $2 p$ bands from the target surface after the first of the four deposition runs, as shown in Fig. 5, indicates considerable differences from those data observed for the HA precursor powder and the target surface prior to deposition. In particular, the sputtered 'annular racetrack' region (A) showed severe phosphate depletion, with a $\mathrm{Ca} / \mathrm{P}$ ratio of 7.80 (Table 3), as determined by analysis of sections of the intact target surface analysed after each individual run. The high-resolution C 1s envelope for region A created after the first sputter deposition run is shown in Fig. 5(a). These data clearly indicate the presence of a very significant $\mathrm{CO}_{3}{ }^{2-}$ peak at $289.7 \mathrm{eV},{ }^{41,42}$ along with a smaller hydrocarbon (C-C and/or $\mathrm{C}-\mathrm{H}$ ) contribution at $285.0 \mathrm{eV}$. The corresponding $\mathrm{O}$ 1s spectral envelope [Fig. 5(b)] again shows the presence 

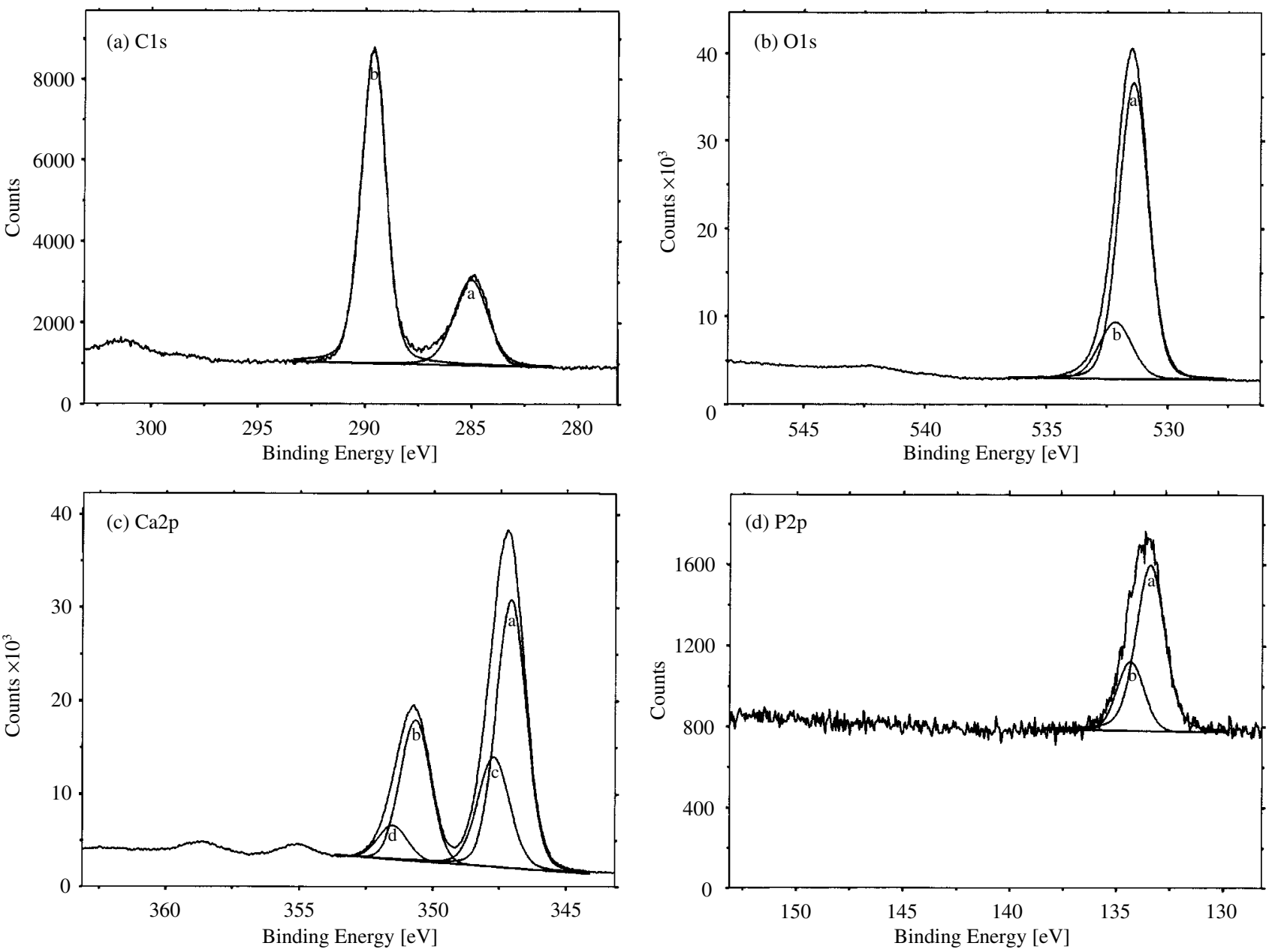

Figure 5. Deconvoluted XPS spectra for (a) C 1s (279-302 eV), (b) O 1s (527-548 eV), (c) Ca 2p (344-364 eV) and (d) P 2p $(129-153 \mathrm{eV}$ ) regions of the sputtered target annulus region $(\mathrm{A})$.

of two distinct bands. The first of these contributions is located at $531.2 \mathrm{eV}$ and is attributed to $\mathrm{O}-\mathrm{P}$ bonding ${ }^{38}$ and the second, found at $532.3 \mathrm{eV}$, is associated with oxygen bonded to carbon or to $\mathrm{OH}^{-}$groups in the HA powder. ${ }^{38}$ It is also possible that this latter peak is due to $\mathrm{P}-\mathrm{O}-\mathrm{H}$ bonding in $\mathrm{HPO}_{4}{ }^{2-}$ groups. ${ }^{44}$

The Ca $2 p$ envelope for the material taken from region A shows an obvious second doublet [Fig. 5(c)]. The Ca 2 $\mathrm{p}_{1 / 2}$ and $\mathrm{Ca} 2 \mathrm{p}_{3 / 2}$ bands fitted to each of the resolved doublets are separated by $\sim 3.5 \mathrm{eV}$ and have the correct $(3: 1)$ relative intensity ratio. The most intense of these two overlapping doublets is present at $347.2 \mathrm{eV}\left(\mathrm{Ca} 2 \mathrm{p}_{3 / 2}\right)$ and $350.7 \mathrm{eV}$ (Ca $2 \mathrm{p}_{1 / 2}$ ) and the second less-intense doublet at $347.8 \mathrm{eV}$ $\left(\mathrm{Ca} 2 \mathrm{p}_{3 / 2}\right)$ and $351.6 \mathrm{eV}\left(\mathrm{Ca} 2 \mathrm{p}_{1 / 2}\right.$ ). These data suggest that the calcium on the surface of the annular region of the sputter target is present in two distinctly different chemical environments. The main doublet at lower binding energy is deemed to be associated with HA. ${ }^{38}$ The most obvious source of the second, less intense, doublet is the occurrence of a $\mathrm{CaCO}_{3}$ species created by the decomposition of the HA material. Additional support for this interpretation comes from the strong $\mathrm{CO}_{3}{ }^{2-}$ contribution to the corresponding $\mathrm{C} 1 \mathrm{~s}$ spectral envelope. However, the binding energy position for the $\mathrm{Ca} 2 \mathrm{p}_{3 / 2}$ line $(347.8 \mathrm{eV})$ is somewhat higher than that generally recorded in the literature for $\mathrm{CaCO}_{3}$, i.e. it is normally in the range $346.5-347.3 \mathrm{eV} .{ }^{45}$ None of the calcium compounds that would result in a binding energy position close to that recorded, namely $\mathrm{CaSO}_{4}$ or $\mathrm{CaF}_{2}$, are likely to be present here and there are no indications in the XPS survey scans for S 2p or F 1s lines that would be associated with these latter species. Hence, it is suggested that this second (weak) Ca $2 \mathrm{p}$ doublet originates mainly from $\mathrm{CaCO}_{3}$ but that the local chemical environment produced by the presence of the other HA degradation products, i.e. OHA, OCP and $\mathrm{Ca}(\mathrm{OH})_{2}$, has shifted the peaks to higher binding energy. The $\mathrm{P} 2 \mathrm{p}$ envelope also has been peak fitted with two peaks, each of which comprise an unresolved doublet, as shown in Fig. 5(d). The most intense of these bands is located at $133.0 \mathrm{eV}$ with the second is centred at $134.3 \mathrm{eV}$ corresponding to $\mathrm{P}-\mathrm{O}$ bond and $\mathrm{P}-\mathrm{O}-\mathrm{H}$ bonding in $\mathrm{HPO}_{4}{ }^{2-}$, respectively. ${ }^{38}$ The latter species again results from HA powder target degradation.

On the basis of these XPS data, the $\mathrm{Ca} / \mathrm{P}$ ratio of the sputtered target has been found to increase dramatically after the first deposition run to a value of 7.80. The $\mathrm{Ca} / \mathrm{P}$ values after each of the subsequent runs (2-4) then decrease slightly in the manner shown in Table 3, but are still much larger than that expected for HA. Moreover, XPS analysis of areas in the middle (M) and the edge (E) of the target surface after sputter run 4 (Table 3 ) clearly indicate that the 
process of phosphate depletion is confined to the annulus region $(\mathrm{A})$ only.

These results suggest that the chemistry of the uppermost surface of the sputtered target annulus region (A) undergoes a dramatic change during sputtering. This degradation is deemed to be associated with breakdown of HA into other calcium phosphate phases, such as $\mathrm{OHA}, \mathrm{OCP}, \mathrm{CaCO}_{3}$ and $\mathrm{Ca}(\mathrm{OH})_{2}$. The most likely explanation for the behaviour noted here is that it results from $\mathrm{Ar}^{+}$ion bombardment, causing preferential sputtering of the $\mathrm{PO}_{4}{ }^{3-}$ and $\mathrm{OH}^{-}$species from the target surface thereby, i.e. leaving a resultant calcium-rich environment. The degree of $\mathrm{PO}_{4}{ }^{3-}$ depletion observed here suggests that the preferential sputtering may be accompanied by the formation of volatile reaction species, e.g. phosphoric acids/phosphorus oxides, which are removed rapidly from the vacuum system under the gas flow conditions employed. The authors have been unable to locate any published literature on the nature of degradation products that might result from ion bombardment of calcium phosphate ceramics. Verification of this behaviour would therefore require detailed optical emission and/or mass spectral analysis of the plasma environment during the r.f. sputtering process. In any case, the loss of the $\mathrm{PO}_{4}{ }^{3-}$ species from the target during sputtering will play an important role in the breakdown of the HA material to form OHA, $\mathrm{OCP}, \mathrm{CaCO}_{3}$ and $\mathrm{Ca}(\mathrm{OH})_{2}$, as suggested by the FTIR, XPS and SEM/EDX results reported here. The presence of large
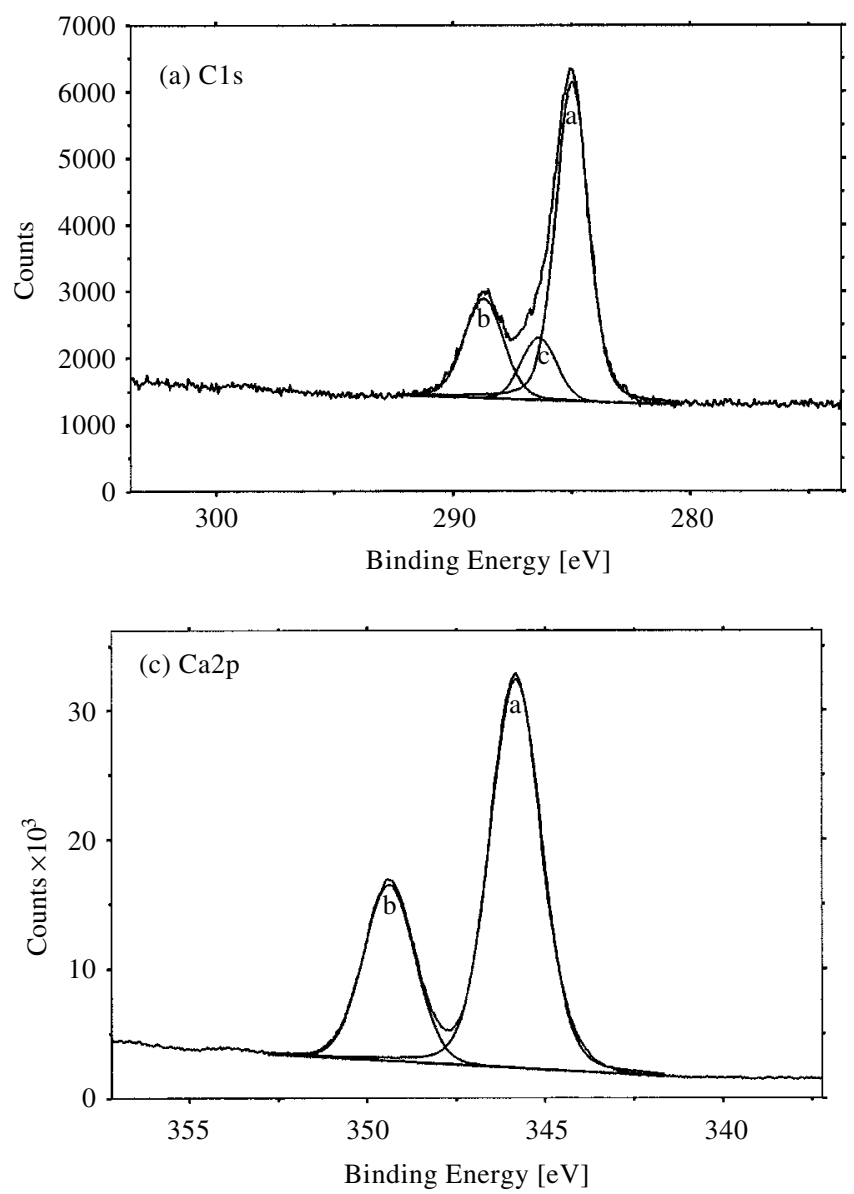

Figure 6. Deconvoluted XPS spectra for (a) C 1s (274-304 eV), (b) O 1s (523-558), (c) Ca 2p (338-358 eV) and (d) P 2p $(124-140 \mathrm{eV})$ regions of a sputter-deposited CaP coating. amounts of $\mathrm{CaCO}_{3}$ and $\mathrm{Ca}(\mathrm{OH})_{2}$ contributes to the high $\mathrm{Ca} / \mathrm{P}$ ratio in the target annulus region $\mathrm{A}$.

\section{Characterization of the sputter-deposited calcium phosphate coatings}

The FTIR spectra for the various $\mathrm{CaP}$ coatings produced in deposition runs 1-4 showed spectral bands associated with P-O stretching vibrations $\left(1200-900 \mathrm{~cm}^{-1}\right.$ ) and bands associated with $\mathrm{O}-\mathrm{P}-\mathrm{O}$ bending vibrations $\left(650-400 \mathrm{~cm}^{-1}\right){ }^{22,24}$ Weak bands associated with carbonate also were observed (1500-1400 and 900-850 $\left.\mathrm{cm}^{-1}\right){ }^{23,24,29-31}$. However, it should be noted that this latter unresolved band also might be associated with $\mathrm{HPO}_{4}{ }^{2-}$ groups. ${ }^{24,30}$ All of the coatings appear to lack the $\mathrm{O}-\mathrm{H}$ vibrational modes that would be expected for $\mathrm{HA}$ at 3570 and $630 \mathrm{~cm}^{-1} .^{24-26}$ Bands between 3700 and $3000 \mathrm{~cm}^{-1}$ associated with adsorbed water molecules, which are commonly observed in such as-deposited coatings, are not detected here. Hence, in the as-deposited state these coatings comprise an amorphous $\mathrm{CaP}$ phase rather than crystalline HA. More importantly, the FTIR results indicate that there is no obvious change in the chemical composition of the coatings as a consequence of repeated sputtering from the same target at $150 \mathrm{~W}$ for up to $12 \mathrm{~h}$.

$\mathrm{X}$-ray photoelectron spectroscopy has been shown to be a very useful method for the characterization of $\mathrm{CaP}$ coatings produced by various deposition techniques. ${ }^{46-48}$ Survey scans obtained for each of the four sequential deposition
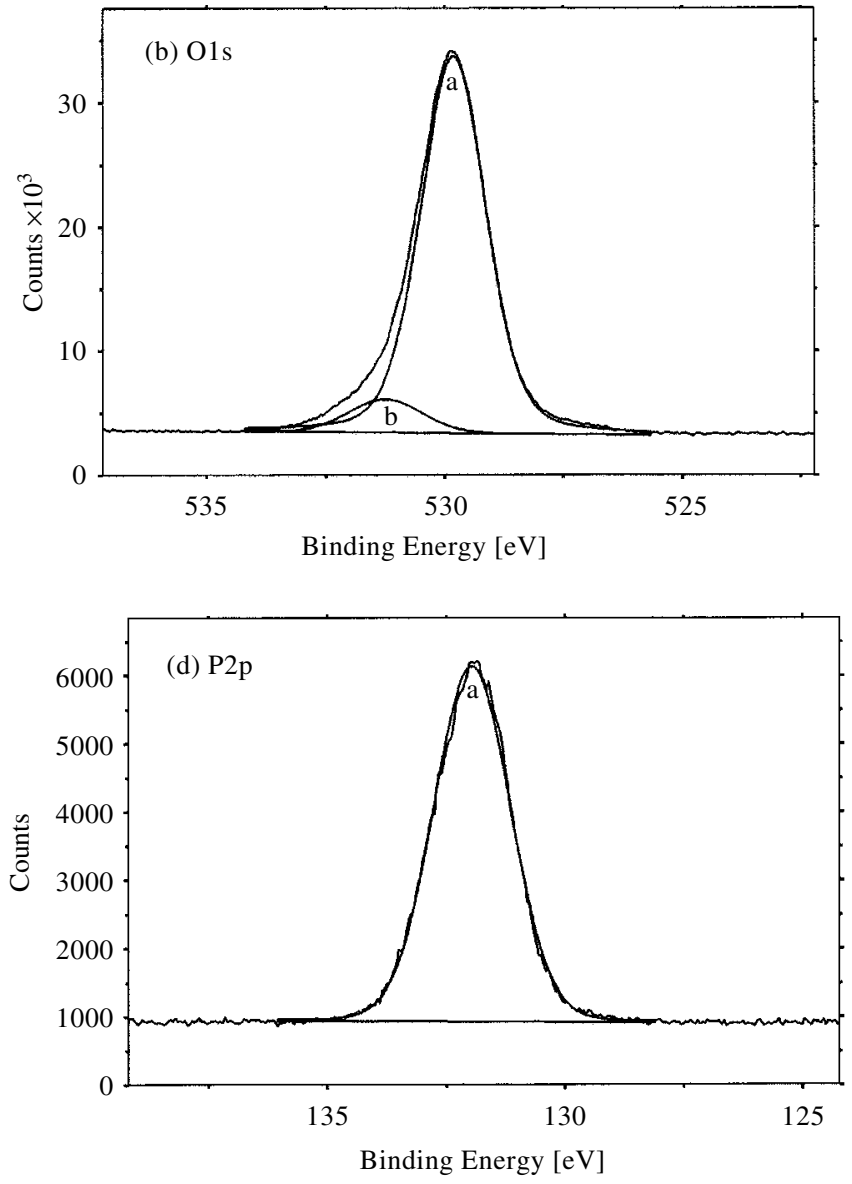
runs (not shown here) were again similar to those observed for the precursor HA powder and target surface. Typical expanded XPS scans for $\mathrm{C} 1 \mathrm{~s}, \mathrm{O} 1 \mathrm{~s}, \mathrm{Ca} 2 \mathrm{p}$ and $\mathrm{P} 2 \mathrm{p}$ regions of the four sputtering runs are shown in Fig. 6. The quantitative data obtained from the XPS analysis of the four (sequential) runs are given in Table 4.

The $\mathrm{C}$ 1s [Fig. 6(a)] and $\mathrm{O}$ 1s [Fig. 6(b)] regions were curve fitted with three and two components, respectively. The various components were assigned as stated previously. The Ca 2 p region [Fig. 6(c)] again exhibits a well-resolved doublet with a Ca $2 p_{3 / 2}$ band at $346.9 \mathrm{eV}$ and a Ca $2 \mathrm{p}_{1 / 2}$ band at $350.4 \mathrm{eV}$ at a relative intensity of $3: 1$. The corresponding P 2p peak [Fig. 6(d)] shows the expected unresolved doublet with a $\mathrm{BE}$ position centred at $133.0 \mathrm{eV}$. The $\mathrm{Ca} / \mathrm{P}$ ratios for each of the coatings, as calculated from these spectral data, are given in Table 4 . In general, these values are significantly higher than the theoretical value of 1.67 expected for HA. ${ }^{3}$ As discussed earlier, targets with stoichiometric HA have been found to produce coatings with higher $\mathrm{Ca} / \mathrm{P}$ ratios when used with plasma vapour deposition techniques. ${ }^{18,19}$ However, most importantly for this study, the XPS results for runs 2-4 indicate that the $\mathrm{Ca} / \mathrm{P}$ ratio of the various films remained fairly constant for each deposition cycle, ranging from 2.09 to 2.29 (Table 4). This is despite the fact that the $\mathrm{Ca} / \mathrm{P}$ ratio of the sputtered annulus region (A) of the target increases dramatically from run 1 to run 4 (see Table 3). This implies that, under the experimental conditions employed here, the driving force for establishing the chemical composition of these sputtered CaP coatings is associated more with the thermodynamics of the nucleation and growth phenomenon at the substrate surface than with the actual target condition. Because this is a line of sight process, the relevant sputtered species must travel upwards through the active plasma region to form a deposit on the substrate. Hence, the potential for energetic interactions to influence the final form of the $\mathrm{CaP}$ thin-film layer, regardless of the nature of the target condition, cannot be neglected. Moreover, calcium enrichment of the CaP sputtered coatings lends support to the theory that volatile phosphorus products are formed at the target surface, because this implies that less of this element is available at the substrate surface to form a HA layer.

The AFM images for CaP sputtered coatings and an uncoated (Ti6Al4V) substrate are shown in Fig. 7. The image for the native substrate surface [Fig. 7(a)] clearly illustrates random scratches ranging in size from 3-5 $\mu \mathrm{m}$ up to $10-20 \mu \mathrm{m}$ across and several microns deep. Small hillocks, pits and fissures, which vary in size up to several microns, are seen regularly across the surface, particularly between the pronounced scratches. The localized $(2.0 \mu \mathrm{m} \times 2.0 \mu \mathrm{m})$ surface roughness $\left(R_{\mathrm{a}}\right)$ for this surface is $69.52 \mathrm{~nm}$. The AFM images obtained for the CaP coatings created in runs 1-3 are shown in Figs 7(b)-(d) and indicate little or no change in the surface. Cross-sectional measurement of the microparticulate features in each case shows that they are in the range 200-800 nm throughout. Several published studies have reported $\mathrm{CaP}$ structures with similar dimensions. ${ }^{49-51}$ The features at the higher end of this range may result from clustering of smaller microparticles. The AFM image for the coating obtained at run 4 [Fig. 7(e)] shows surface features that are less well defined than those created in runs $1-3$. This suggests that the $\mathrm{CaP}$ coating morphology may be starting to be influenced by degradation of the target annulus region (A). The calculated surface roughness values $\left(R_{\mathrm{a}}\right)$ for the CaP surfaces, as reported in Table 5 , are considerably lower than that observed for the native Ti6Al4V substrate surface. This suggests that significant 'in-filling' of the substrate surface features by $\mathrm{CaP}$ has occurred.

\section{CONCLUSIONS}

Multiple sputter deposition from a single HA target has been carried out to produce a sequential series of four $\mathrm{CaP}$ coatings on Ti6Al4V substrates. The target annulus region showed severe surface degradation accompanied by significant phosphorus depletion after the first deposition run. This very localized damage is characteristic of the use of an r.f. magnetron sputter source. By the forth sputtering cycle, the $\mathrm{Ca} / \mathrm{P}$ ratio was four times that expected for HA. The non-stoichiometric loss of the phosphorus suggests

Table 4. The XPS data for coatings deposited during sputter runs 1-4

\begin{tabular}{|c|c|c|c|c|c|c|c|c|c|c|}
\hline \multirow[b]{2}{*}{ Sample } & \multicolumn{5}{|c|}{ Peak position-binding energy $(\mathrm{eV})$} & \multicolumn{4}{|c|}{$\%$ Atomic concentration } & \multirow[b]{2}{*}{$\mathrm{Ca} / \mathrm{P}$} \\
\hline & $\mathrm{C} 1 \mathrm{~s}$ & $\mathrm{O} 1 \mathrm{~s}$ & $\mathrm{Ca} 2 \mathrm{p}_{3 / 2}$ & $\mathrm{Ca} 2 \mathrm{p}_{1 / 2}$ & P $2 p$ & C 1s & $\mathrm{O} 1 \mathrm{~s}$ & Ca $2 p$ & P $2 p$ & \\
\hline Run 1 & $\begin{array}{l}285.0(1) \\
285.9(2) \\
288.8(3)\end{array}$ & $\begin{array}{l}530.8(1) \\
532.2(2)\end{array}$ & 346.9 & 350.4 & 133.0 & 19.5 & 52.4 & 19.4 & 8.8 & 2.20 \\
\hline Run 2 & $\begin{array}{l}285.0(1) \\
286.0(2) \\
288.9(3)\end{array}$ & $\begin{array}{l}531.1(1) \\
532.5(2)\end{array}$ & 346.5 & 350.1 & 132.6 & 19.4 & 52.6 & 19.5 & 8.5 & 2.29 \\
\hline Run 3 & $\begin{array}{l}285.0(1) \\
286.2(2) \\
288.1(3)\end{array}$ & $\begin{array}{l}531.2(1) \\
531.4(2)\end{array}$ & 346.8 & 350.4 & 132.8 & 18.2 & 53.9 & 19.7 & 8.7 & 2.26 \\
\hline Run 4 & $\begin{array}{l}285.0(1) \\
286.4(2) \\
288.1(3)\end{array}$ & $\begin{array}{l}531.0(1) \\
532.3(2)\end{array}$ & 347.2 & 350.6 & 133.3 & 15.2 & 54.1 & 20.7 & 9.9 & 2.09 \\
\hline
\end{tabular}




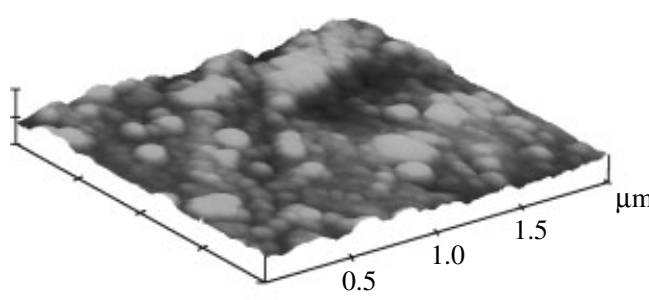

(b)

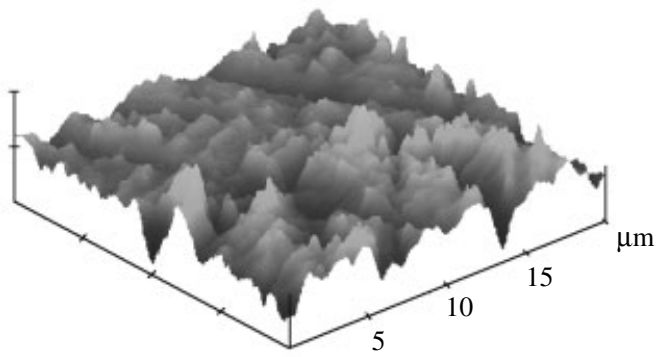

(a)

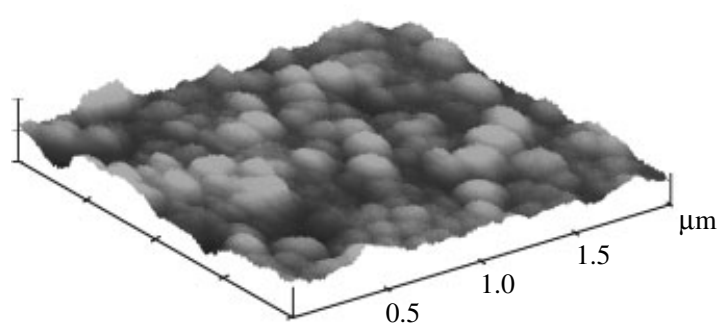

(d)

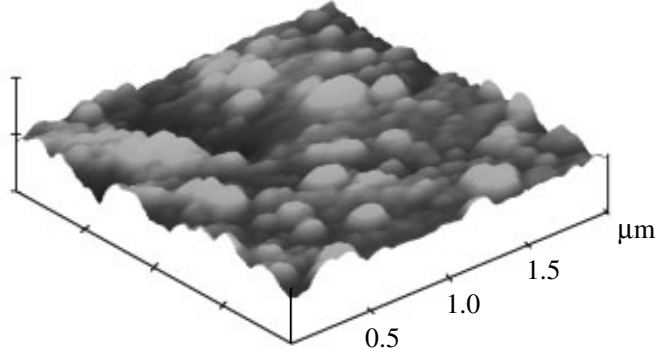

(c)

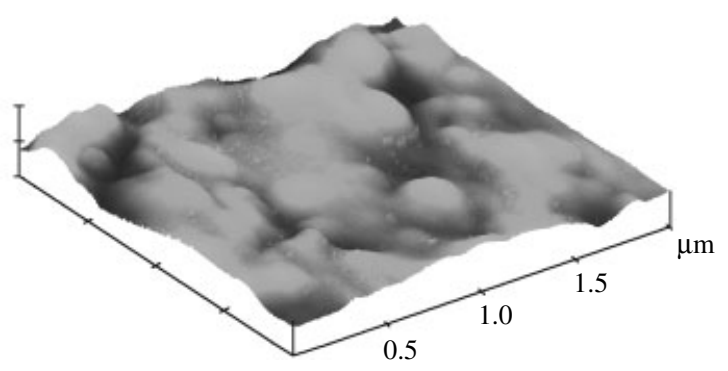

(e)

Figure 7. The AFM images $(2 \mu \mathrm{m} \times 2 \mu \mathrm{m})$ of $\mathrm{CaP}$ coatings sputter deposited onto Ti6Al4V substrates, showing: (a) the native Ti6Al4V substrate; (b) run 1; (c) run 2; (d) run 3; (e) run 4.

Table 5. The AFM $(2 \mu \mathrm{m} \times 2 \mu \mathrm{m})$-derived surface roughness $\left(R_{\mathrm{a}}\right)$ values for the Ti6Al4V substrate and sputter-deposited CaP coatings from runs $1-4$

\begin{tabular}{lc}
\hline Sample & $\begin{array}{r}\text { Surface roughness } \\
\left(R_{\mathrm{a}}\right)(\mathrm{nm})\end{array}$ \\
\hline Substrate (Ti6AlkV) & 43.6 \\
$\mathrm{CaP}$, run 1 & 24.3 \\
$\mathrm{CaP}$, run 2 & 19.8 \\
$\mathrm{CaP}$, run 3 & 14.7 \\
$\mathrm{CaP}$, run 4 & 19.7 \\
\hline
\end{tabular}

preferential sputtering of this element by $\mathrm{Ar}^{+}$to leave a calcium-rich surface region.

The bioceramic coatings produced after each of the sputter cycles contained both $\mathrm{Ca}^{2+}$ and $\mathrm{PO}_{4}{ }^{3-}$ species and were clearly deficient in $\mathrm{OH}^{-}$and $\mathrm{PO}_{4}{ }^{3-}$, as determined by FTIR and XPS analyses. In general, the $\mathrm{Ca} / \mathrm{P}$ ratios recorded for the various coatings were consistently higher than would be expected for stoichiometric HA but not as high as those observed for the residual target surfaces. On the basis of this observation, it is proposed that phosphorus depletion is accompanied by the formation of volatile reaction products that are removed from the vacuum system and therefore are unavailable for subsequent HA formation at the substrate surface. More importantly for this study, the $\mathrm{Ca} / \mathrm{P}$ ratio remained quite consistent across the four individual coatings examined.

The AFM analysis of the CaP coatings showed identical morphology for runs 1-3 but indicated that after the fourth deposition run there were noticeable changes in the surface structure. In particular, the well-defined microparticulate features observed in the earlier images were much less prominent. Hence, even though it is clear that severe degradation of the HA target material is occurring in the sputtered annulus region, this does not seem to have a detrimental influence on the properties of the resultant coatings until after the third deposition cycle. Three deposition runs constitutes a total of $9 \mathrm{~h}$ of sputtering time and therefore this may represent a good measure of HA powder target longevity during coating experiments of the type studied here.

\section{Acknowledgements}

The authors would like to thank the Research Unit for Surfaces, Transforms and Interfaces (RUSTI), CLRC, Daresbury, UK for the Scienta ESCA 300 Instrument time and to Drs Graham Beamson and Danny Law for assistance with the XPS analysis. We are also grateful to Dr R. J. Turner, Department of Pure and Applied Physics, Queens University, Belfast for his assistance with the AFM analysis.

\section{REFERENCES}

1. Yan W, Nakamura T, Kawanabe K, Nishigochi S, Oka M, Kokubo T. Biomaterials 1997; 18: 1185.

2. Hench LL. J. Am. Ceram. Soc. 1998; 8: 11705. 
3. Ravaglioli A, Krajewski A. Bioceramics: Materials Properties Applications. Chapman \& Hall: London, 1992.

4. Cheang P, Khor KA. Biomaterials 1996; 17: 537.

5. Wolke JGC, van Dijk K, Schaeken HG, de Groot K, Jansen JA. J. Biomed. Mater. Res. 1994; 28: 1477.

6. Yamashita K, Yonehara E, Ding X, Nagai M, Umegaki T. J. Biomed. Mater. Res. (Appl. Biomater.) 1998; 43: 46.

7. Li T, Lee J, Kobayashi T, Aoki H. J. Mater. Sci.: Mater. Med. 1996; 7: 355 .

8. Wang CK, Lin JHC, Ju CP, Ong HC, Chang RPH. Biomaterials 1997; 18: 1331.

9. Guipont V, Espanol M, Borot F, Llorca-Isern N, Jeandin M, Khor KA, Cheang P. Mater. Sci. Eng. A 2002; 325: 9.

10. Vogel J, Ruessel C, Hartmann P, Vizethum F, Bergner N. CFI Ceram. Forum Int. 1999; 76: 28.

11. Van Dijk K, Schaeken HG, Wolke JGC, Maree CHM, Habraken FHPM, Verhoeven J, Jansen JA. J. Biomed. Mater. Res. 1995; 29: 269.

12. Van Dijk K, Schaeken HG, Maree CHM, Verhoeven J, Wolke JGC, Habraken FHPM, Jansen JA. Surf. Coat. Tech. 1995; 76/77: 206.

13. Love E, Weimper M, Boyd A, Meenan BJ, Akay M. Key Eng. Mater. 2001; 192-195: 255.

14. Van Dijk K, Schaeken HG, Wolke JGC, Jansen JA. Biomaterials 1996; 17: 405.

15. Jansen JA, Wolke JGC, van der Waerden JPCM, de Groot K. Clin. Oral Implic. Res. 1993; 4: 28.

16. Wolke JGC, de Groot K, Jansen JA. J. Mater. Sci. 1998; 33: 3371.

17. Lo WJ, Grant DM. J. Biomed. Mater. Res. 1999; 46: 408.

18. Yamashita K, Matsuda M, Arashi T, Umegaki T. Biomaterials 1998; 19: 1239.

19. Yamashita K, Yagi T, Hamagami J, Umegaki T. Bioceramics 1996; 9: 337-340.

20. Liu Q, de Wijn JR, van Blitterswijk CA. J. Biomed. Mater. Res. 1998; 40: 490.

21. Meenan BJ, Boyd A, Love E, Akay M. Key Eng. Mater. 2001; 192-195: 15

22. Liu DM. J. Mater. Sci.: Mater. Med. 1997; 8: 227.

23. Rehman I, Bonfield W. J. Mater. Sci.: Mater. Med. 1997; 8: 1.

24. Arias JL, Garcia-Sanz FJ, Mayor MB, Chiussi, Pou J, Leon B, Perez-Amor M. Biomaterials 1998; 19: 883.

25. Gonzalez-Diaz PF, Santos M. J. Solid State Chem. 1977; 22: 193.

26. Slosarczyk A, Paluszkiewicz C, Gawlicki M, Paszkiewicz Z. Ceram. Int. 1997; 23: 297.

27. Ikoma T, Yamazaki A, Nakamura S, Akao M. J. Solid State Chem. 1999; 144: 272.
28. Han Y, Xu K, Lu J. J. Mater. Sci.: Mater. Med. 1999; 10: 243.

29. Doi Y, Shibutani T, Moriwaki Y, Kajimoto T, Iwayama Y. J. Biomed. Mater. Res. 1998; 391: 603.

30. Apfelbaum F, Diab H, Mayer I, Featherstone JDB. J. Inorg. Biochem. 1992; 45: 177.

31. Li P, Kangasniemi I, de Groot K, Kokubo T. J. Am. Ceram. Soc. 1994; 77: 1307.

32. Park E, Condrate RA, Lee D. Mater. Lett. 1998; 36: 38.

33. Liao CJ, Lin FH, Chen KS, Sun JS. Biomaterials 1999; 20: 1807.

34. Shirkhanzadeh M, Azadegan M. J. Mater. Sci.: Mater. Med. 1998; 9: 385.

35. Mahapatra PP, Mishra B. Current Sci. 1990; 59: 993.

36. Mayor MB, Arias JL, Garcia-Sanz FJ, Chiussi S, Pou J, Leon B, Perez-Amor M. Bioceramics 1998; 11: 209.

37. Chusuei C, Goodman DW, Van Stipdonk MJ, Justes DR, Schweikert EA. Anal. Chem. 1999; 71: 149.

38. Ong JL, Lucas LC, Raikar GN, Weimer JJ, Gregory JC. Coll. Surf. A: Physiochem. Eng. Aspects 1994; 87: 151.

39. Tanahashi M, Yao T, Kokubo T, Minoda M, Miyamoto T, Nakamura T, Yamamuro T. J. Biomed. Mater. Res. 1995; 29: 249.

40. Tanahashi M, Yao T, Kokubo T, Minoda M, Miyamoto T, Nakamura T, Yamamuro T. J. Appl. Biomater. 1994; 5: 339.

41. Jha LJ, Santos JD, Knowles JC. J. Biomed. Mater. Res. 1996; 31: 481.

42. Santos JD, Jha LJ, Monteiro FJ. J. Mater. Sci.: Mater. Med. 1996; 7: 181.

43. Nguyen TP, Dupraz A. J. Biomater. Sci. Polym. Ed. 1996; 8: 141.

44. Amrah-Bouali S, Rey C, Lebugle A, Bernache D. Biomaterials 1994; 15: 269.

45. Moulder JF, Stickle WF, Sobol PE, Bomben K. Handbook of X-ray Photoelectron Spectroscopy (2nd edn). Perkin-Elmer Corporation: Eden Praerie, MN, 1992; and references therein.

46. Kaciulis S, Mattogno G, Napoli A, Bemporad E, Ferrari F, Montenero A, Gnappi G. J. Electron Spectrosc. Relat. Phenom. 1998; 95: 61.

47. Kaciulis S, Mattogno G, Pandolfi L, Cavalli M, Gnappi G, Montenero A. Appl. Surf. Sci. 1999; 151: 1.

48. Battistoni C, Casaletto MP, Ingo GM, Kaciulis S, Mattogno G, Pandolfi L. Surf. Interface Anal. 2000; 29: 773.

49. Siperko LM, Landis WJ. Analyst 1994; 119: 1935.

50. Antanov EN, Bagratashvili VN, Popov VK, Sobol EN, Davies MC, Tendler SJB, Roberts CJ, Howdle SM. Biomaterials 1997; 18: 1043.

51. Meenan BJ, Boyd A, Leyland NS, Love E, Akay M. Bioceramics vol. 12, Ohgushi H (ed.). World Scientific Publishing: Singapore, 1999; 471-474. 